\title{
ANALISIS PENGUKURAN KINERJA PT AGUNG PODOMORO LAND TBK DENGAN METODE BALANCED SCORECARD (BSC)
}

\author{
Indra Gunawan \\ Program Studi Magister Manajemen Universitas Tarumanagara \\ indragun@gmail.com
}

Masuk : 09-06-2020, revisi : 26-06-2020 diterima untuk diterbitkan : 26-06-2020

\begin{abstract}
Balanced scorecard is a strategic management performance metric used to identify and improve various internal business functions and their resulting external outcomes. Balanced Scorecard based on four perspectives, which is employee learning and growth, business process, customer and financial perspective. However, this research will limit the elaboration based on employee learning and growth perspective only as the basic to successful achievement of the company. These aspects are assisted by employee satisfaction variable, coaching or training conducted or received by the employee, productivity and percentage of employee turnover within one company.

Formulation of hypothesis for the research is that employee learning and growing perspective affect human resource performance in PT Agung Podomoro Land Tbk. Number of samples used were 35 people with 33 questions. Data sample were obtained using online google form questionnaire method using likert indicator and data validity or reliability was performed using SPSS v.25 method. Research variable shows that employee working satisfaction variable (X1) is the most dominant variable. This hypothesis is tested and proven by using test $\mathrm{T}$ in linear regression analysis technique. The result shows $\mathrm{T}_{\text {count }} 2,616>\mathrm{T}_{\text {table }} 2,042$ with level of trust $\boldsymbol{\alpha} 0,05$.
\end{abstract}

Abstrak: Balanced scorecard adalah metrik kinerja manajemen strategis yang digunakan untuk mengidentifikasi dan meningkatkan berbagai fungsi bisnis internal serta hasil eksternal yang di hasilkannya. Balanced Scorecard memiliki empat perspektif yang mendasari yaitu perspektif pembelajaran dan pertumbuhan karyawan, perspektif bisnis proses, perspektif pelanggan dan perspektif finansial. Penelitian ini di fokuskan pada perspektif pembelajaran dan pertumbuhan karyawan, sebagai akar dari proses menuju kesuksesan bagi perusahaan. Dibantu dengan varibel kepuasan karyawan dalam bekerja, pelatihan ataupun training yang dilakukan oleh karyawan, serta turnover karyawan dalam perusahaan dan produktivitas karyawan.

Hipotesis penelitian ini di rumuskan bahwa perspektif pembelajaran dan pertumbuhan karyawan berpengaruh terhadap kinerja sumber daya manusia pada PT Agung Podomoro Land Tbk. Jumlah sampel yang digunakan sebanyak 35 orang dengan 33 pertanyaan. Data yang dikumpulkan menggunakan kuesioner online Google Form dengan satuan skala Likert. Uji validitas dan uji reliabilitas di lakukan dengan menggunakan SPSS versi 25. Variabel penelitian menunjukkan kepuasan karyawan dalam bekerja $\left(\mathrm{X}_{1}\right)$ merupakan variabel yang paling dominan terhadap kinerja sumber daya manusia. Hipotesa ini dites dan dibuktikan melalui uji $\mathrm{T}$ dalam teknik analisa regresi liner. Hasilnya menunjukan bahwa $\mathrm{T}_{\text {hitung }}$ sebesar 2,616 $>\mathrm{T}_{\text {tabel }}$ 2,042 dengan tingkat kepercayaan $\alpha 0,05$.

Keywords: Balanced Scorecard, Employee Satisfaction, Performance, Human Resources 


\section{PENDAHULUAN}

Pada lingkungan yang terus berubah, manajemen perusahaan perlu mendesain, memasang, mengoperasikan sistem perumusan strategi, sistem perencanaan strategik, dan sistem penyusunan program serta memotivasi seluruh personil perusahaan untuk bersamasama membangun perusahaan mereka. Pengukuran kinerja yang menitikberatkan pada sektor keuangan saja kurang mampu mengukur kinerja harta-harta tak tampak (intangible assets) dan harta-harta intelektual (sumber daya manusia) perusahaan.

Pengukuran kinerja yang efektif mampu menilai keseluruhan perspektif dalam perusahaan di mana pengukuran kinerja tersebut terangkum dalam suatu sistem pengukuran strategis yakni Balanced Scorecard. Balanced Scorecard (BSC) merupakan alat manajemen kontemporer yang didesain untuk meningkatkan kemampuan perusahaan dalam melipatgandakan kinerja keuangan secara berkesinambungan (sustainable outstanding financial performance) (Mulyadi, 2009:3).

PT Agung Podomoro Land Tbk (APL) adalah adalah pemilik, pengembang dan pengelola beragam produk dan proyek real estate, ritel, komersial dan residensial dengan kepemilikan yang beragam tersebar di Indonesia. APL memiliki model pengembangan properti yang terintegrasi, mulai dari akuisisi dan/atau pengadaan lahan, desain dan pengembangan, pengelolaan proyek, penjualan, penyewaan dan pemasaran area komersial, hingga pada pengoperasian dan pengelolaan superblok, pusat perbelanjaan, perkantoran, hotel, apartemen dan perumahan dan juga di kenal sebagai pelopor pengembangan superblok. APL didirikan pada tanggal 30 Juli 2004 dengan nama PT Tiara Metropolitan Jaya.

Sejak tahun 2012, perusahaan menerapkan balanced scorecard menjadi alat atau perlengkapan departemen sumber daya manusia untuk menerapkan berbagai fungsi di sumber daya manusia tersebut. Dalam hal karir, kompensasi, benefit atau hal lainnya perusahaan biasanya memberikan perhatian terbesar kepada departemen utama (core function), sedangkan departemen pendukung (support function) biasanya sebaliknya. Metode balanced scorecard tidak mengenal pembedaan ini, maka baik departemen core function maupun support function sama-sama dinilai dan diberikan target yang sesuai dengan tanggung jawabnya masing-masing.

Berdasarkan masalah muncul di atas, maka penulis merumuskan masalah bagaimana efektifitas pengukuran kinerja dengan menggunakan balanced scorecard pengaruhnya terhadap kinerja sumber daya manusia pada PT Agung Podomoro Land Tbk.

\section{LANDASAN TEORI}

Kinerja berasal dari kata job performance atau actual performance yang berarti prestasi kerja atau prestasi sesungguhnya yang di capai oleh seseorang. Pengertian kinerja (prestasi kerja) adalah hasil kerja secara kualitas dan kuantitas yang dicapai oleh seorang pegawai dalam melaksanakan fungsinya sesuai dengan tanggung jawab yang diberikan kepadanya. Performance atau kinerja merupakan hasil atau keluaran dari suatu proses (Nurlaila, 2010:71).

Pengertian Pengukuran Kinerja menurut Mulyadi (2001: 353) mendefinisikan "Pengukuran kinerja adalah penentuan secara periodik efektifitas operasional suatu organisasi, bagian organisasi dan personelnya, berdasarkan sasaran, standar dan kriteria yang telah ditetapkan sebelumnya".

Balanced scorecard mencakup perspektif yang luas yaitu keuangan, pelanggan, proses bisnis internal, serta pembelajaran dan bahan. Selain itu berbagai sasaran strategik yang dirumuskan dalam sistem manajemen strategik tradisional tidak koheren satu dengan yang lainnya, sedangkan berbagai sasaran strategik sistem manajemen strategik kontemporer dirumuskan secara koheren. Di samping itu, balanced scorecard menjadikan sistem manajemen strategik kontemporer memiliki karakteristik yang tidak dimiliki oleh sistem manajemen strategik tradisional, yaitu dalam karakteristik keterukuran dan kesimbangan. 
Dalam perspektif pembelajaran dan pertumbuhan karyawan, terdapat beberapa indikator yang menjadi bagian penting dalam keberhasilan perspektif ini. Indikator tersebut adalah kepuasan karyawan, pelatihan, tingkat turnover, dan produktivitas karyawan.

1. Menurut Blau, dalam Panggabean (2004) kepuasan kerja adalah kepuasan terhadap setiap perlakuan yang mereka terima di tempat kerja.

2. Pelatihan dapat didefinisikan sebagai suatu cara yang digunakan untuk memberikan atau meningkatkan keterampilan yang dibutuhkan untuk melaksanakan pekerjaannya sekarang.

3. Turnover karyawan merupakan hal yang ingin dihindari oleh perusahaan, di karenakan dengan tingginya nilai turnover ini akan menyebabkan biaya rekrutmen, pelatihan yang sudah diberikan hilang akibat keluarnya karyawan perusahaan.

4. Produktivitas karyawan perusahaan harus dipacu oleh seluruh pimpinan perusahaan, karena dengan demikian perusahaan akan beroperasi dengan maksimal. Jika terdapat unit maupun pribadi karyawan perusahaan yang belum memiliki produktivitas tinggi, maka tugas pimpinanlah untuk memberikan motivasi, pelatihan, dan seterusnya kepada karyawan tersebut.

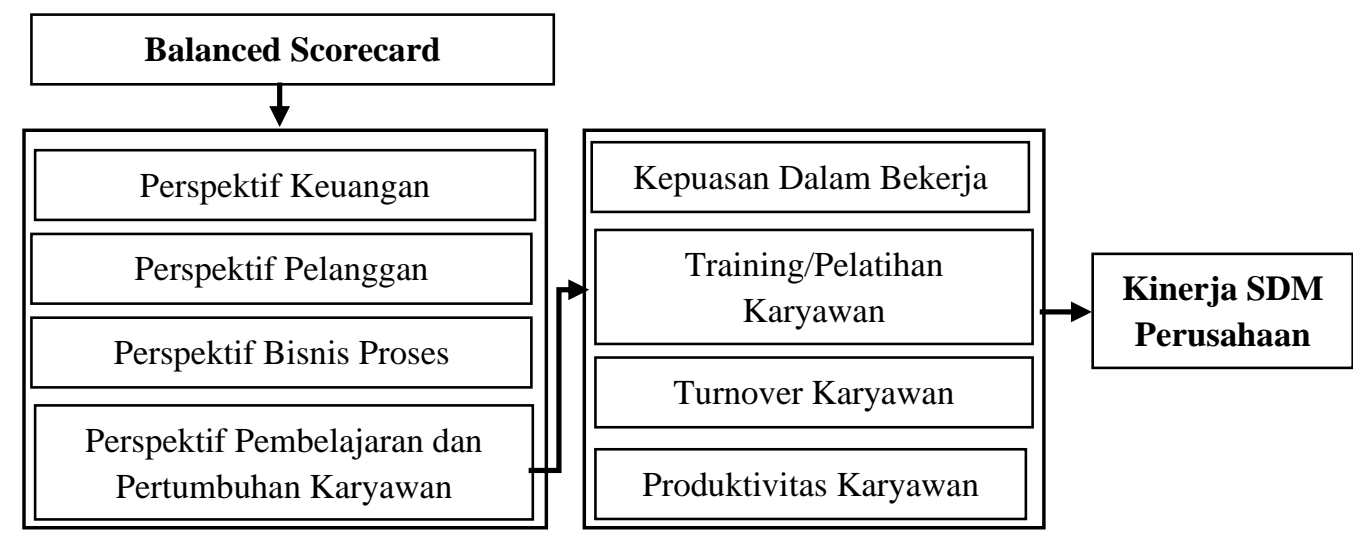

Gambar 1

Kerangka Pemikiran Analisis Balanced Scorecard sebagai Suatu Alat Pengukuran Kinerja Sumber Daya Manusia PT Agung Podomoro Land Tbk.

\section{METODE PENELITIAN}

\section{Jenis dan Periode Penelitian}

Agar penelitian ini lebih terarah serta sesuai dengan tujuan yang diinginkan, penulis menggunakan jenis penelitian kuantitatif dan kualitatif untuk mengolah data-data yang diperoleh dari lokasi penelitian. Penelitian ini juga dapat digolongkan sebagai jenis penelitian kuantitatif dengan menggunakan metode survei, yaitu metode yang digunakan untuk mendapatkan data dari tempat tertentu yang alamiah (bukan buatan), tetapi peneliti melakukan perlakuan dalam pengumpulan data, misalnya dengan mengedarkan kuisioner, tes, dan wawancara terstruktur (Sugiyono, 2012:6).

\section{Teknik Pengambilan Sampel dan Periode Penelitian}

Teknik pengambilan sampel yang digunakan adalah teknik simple random sampling. Sampel yang di ambil adalah karyawan PT Agung Podomoro Land Tbk dari mulai pangkat Officer sampai dengan Manager, dimana pada pangkat tersebut sudah diterapkan metode Balanced Scorecard. Kuisioner disebar melalui pengisian formulir online dari Google atau Google Form dimulai sejak Mei 2020 sampai dengan Juni 2020. Dari pengisian kuisioner tersebut didapatkan sebanyak 35 responden yang mengisi formulir. 


\section{Identifikasi Varibel Penelitian}

Memperjelas antara variabel yang satu dengan yang lain, maka variabel dalam penelitian dibedakan menjadi:

a. Variabel Independen (X) adalah fenomena atau gejala yang mempengaruhi atau menjadi sebab perubahannya atau timbulnya variabel terikat (Y). Dalam penelitian ini yang menjadi variabel bebas (X), adalah dimensi kepuasan karyawan dalam bekerja $\left(\mathrm{X}_{1}\right)$, pelatihan karyawan $\left(\mathrm{X}_{2}\right)$, turnover karyawan $\left(\mathrm{X}_{3}\right)$, dan produktivitas karyawan $\left(\mathrm{X}_{4}\right)$.

b. Variabel dependen (Y) adalah merupakan variabel yang dipengaruhi atau menjadi akibat karena adanya variabel bebas $(\mathrm{X})$. Dalam penelitian ini yang menjadi variabel terikat adalah kinerja sumber daya manusia perusahaan PT Agung Podomoro Land Tbk. (Y1).

\section{ANALISIS DAN PEMBAHASAN}

\section{Karakteristik Responden}

Dari hasil kuisioner yang sudah disebar dan diinput, di dapat informasi sebagai berikut:

Tabel 1

Data Frekuensi dan Persentase Responden

\begin{tabular}{|c|c|c|c|}
\hline \multicolumn{2}{|c|}{ Karakteristik Responden } & Frekuensi & Persentase \\
\hline \multirow{3}{*}{ Pangkat } & Manager & 8 & $23 \%$ \\
\hline & Supervisor & 13 & $37 \%$ \\
\hline & Officer & 14 & $40 \%$ \\
\hline \multirow{2}{*}{ Jenis Kelamin } & Pria & 22 & $63 \%$ \\
\hline & Wanita & 13 & $37 \%$ \\
\hline \multirow{4}{*}{ Usia } & $20-30$ & 9 & $26 \%$ \\
\hline & $31-40$ & 9 & $26 \%$ \\
\hline & $41-50$ & 9 & $26 \%$ \\
\hline & $>50$ & 8 & $23 \%$ \\
\hline \multirow{4}{*}{ Masa Kerja } & $1-2$ & 5 & $14 \%$ \\
\hline & $3-4$ & 2 & $6 \%$ \\
\hline & $5-10$ & 13 & $37 \%$ \\
\hline & $>10$ & 15 & $43 \%$ \\
\hline
\end{tabular}

Tabel 1 menunjukan sebanyak total 35 responden yang mengisi kuisioner dan masih bekerja bekerja di PT Agung Podomoro Land Tbk.

\section{Analisis Deskriptif Variabel}

Instrumen yang digunakan dalam penelitian ini adalah kuesioner. Jumlah pertanyaan seluruhnya adalah 8 butir untuk varibel $\mathrm{X}_{1}, 6$ butir untuk variabel $\mathrm{X}_{2}, 6$ butir untuk variable $\mathrm{X}_{3}$, 6 butir untuk variabel $\mathrm{X}_{4}$ dan 7 butir untuk variabel $\mathrm{Y}$, jadi total seluruh pertanyaan adalah 33 butir. Tabel berikut adalah hasil pengolahan data primer yang merupakan analisis deskriptif frekuensi penelitian pendapat responden mengenai Varibel Kepuasan Karyawan dengan keterangan judul berikut: STS = Sangat Tidak Setuju; TS = Tidak Setuju; R= Ragu-ragu; $\mathrm{S}=$ Setuju; SS = Sangat Setuju.

\section{Tabel 2}

\section{Rekapitulasi Penjelasan Responden}

\begin{tabular}{|c|c|c|c|c|c|c|c|c|c|c|c|c|}
\hline & \multicolumn{2}{|c|}{ STS } & \multicolumn{2}{|c|}{ TS } & \multicolumn{2}{|r|}{$\mathrm{R}$} & \multicolumn{2}{|r|}{$\mathrm{S}$} & \multicolumn{2}{|c|}{ SS } & \multicolumn{2}{|c|}{ TOTAL } \\
\hline & $\mathrm{F}$ & $\%$ & $\mathrm{~F}$ & $\%$ & $\mathrm{~F}$ & $\%$ & $\mathrm{~F}$ & $\%$ & $\mathrm{~F}$ & $\%$ & $\mathrm{~F}$ & $\%$ \\
\hline Rata-rata 33 butir pertanyaan & & $\mathbf{0 , 0 0}$ & & 1,82 & & 6,49 & & 17,66 & & 74,03 & 35 & \\
\hline
\end{tabular}

Dari semua pertanyaan yang diisi oleh responden didapatkan secara rata-rata $17,66 \%$ responden menyatakan setuju, dan $74,03 \%$ responden menyatakan sangat setuju, sehingga semua indikator memiliki peranan penting terhadap kinerja karyawan. Hal ini menunjukkan secara umum responden menyatakan kepuasan karyawan, pelatihan, turnover, produktivitas perusahaan mempunyai korelasi yang kuat dalam peningkatan kinerja karyawan perusahaan. 


\section{Uji Realibilitas}

Dari tabel 3 di bawah diketahui $\mathrm{N}$ of Items adalah 33 responden item dengan nilai Cronbach's Alpha untuk semua pertanyaan > 0,60. Maka dapat disimpulkan bahwa semua item pertanyaan kuisioner adalah realiabel atau konsisten.

Tabel 3

Uji Validitas

\begin{tabular}{|c|c|}
\hline \multicolumn{2}{|c|}{ Reliability Statistics } \\
\hline $\begin{array}{c}\text { Cronbach's } \\
\text { Alpha }\end{array}$ & $\mathrm{N}$ of Items \\
\hline ,759 & 33 \\
\hline
\end{tabular}

\section{Uji Validitas}

Uji Validitas digunakan untuk mengukur ketepatan kuesioner terhadap variabel-variabel pertanyaannya. Pada uji validitas ini, akan digunakan nilai koefisien pearson. Suatu item pertanyaan pada kuesioner dikatakan valid jika nilai r-hitung lebih besar dari r-tabel. (r-hitung $>$ r-tabel). Pada penelitian ini, nilai r-tabel dapat diketahui yaitu sebesar 0,29 yang diperoleh dari tabel dengan degree of freedom (df) sebesar 31 pada signifikansi 5\%. Untuk itu dapat ditarik kesimpulan terlihat bahwa hasil uji validitas menunjukkan bahwa 28 pertanyaan valid sedangkan 5 pertanyaan tidak valid.

\section{Hasil Uji Koefisien Regresi}

Nilai thitung akan dibandingkan dengan nilai t tabel dengan tingkat kesalahan $(\alpha)=5 \%$ dan derajat kebebasan $(\mathrm{df})=(33-2)$, maka diperoleh nilai $\mathrm{t}$ tabel $=2,042$. Berdasarkan hasil uji t hitung pada table 4, nilai t hitung untuk variabel kepuasan karyawan dalam bekerja $\left(\mathrm{X}_{1}\right)=$ $2,616>2,042$. Berdasarkan kriteria tersebut berarti kepuasan karyawan dalam bekerja $\left(\mathrm{X}_{1}\right)$ secara parsial berpengaruh signifikan dan nyata terhadap kinerja karyawan, sedangkan untuk pelatihan, turnover, dan produktivitas di dapatkan nilai t hitung $<2,042$, sehingga di anggap kurang memiliki peranan penting terhadap kinerja karyawan.

\section{Tabel 4}

Hasil Uji Statistik Koefisien Regresi

\begin{tabular}{|l|r|r|c|r|r|}
\hline \multirow{2}{*}{ Model } & \multicolumn{2}{|c|}{$\begin{array}{c}\text { Unstandardized } \\
\text { Coefficients }\end{array}$} & $\begin{array}{c}\text { Standardized } \\
\text { Coefficients }\end{array}$ & \multirow{2}{*}{ t } & \multirow{2}{*}{ Sig. } \\
\cline { 2 - 4 } & \multicolumn{1}{|c|}{ B } & Std. Error & Beta & & \\
\hline (Constant) & 13,889 & 11,327 & & 1,226 & 0,230 \\
\hline Kepuasan & 0,455 & 0,174 & 0,463 & 2,616 & 0,014 \\
\hline Pelatihan & $-0,124$ & 0,134 & $-0,155$ & $-0,926$ & 0,362 \\
\hline Turnover & $-0,354$ & 0,197 & $-0,328$ & $-1,795$ & 0,083 \\
\hline Produktivitas & 0,514 & 0,307 & 0,322 & 1,678 & 0,104 \\
\hline
\end{tabular}

\section{KESIMPULAN DAN SARAN \\ Kesimpulan}

Hasil uji validitas dan realibilitas kuisioner yang sudah diisi responden menunjukan pertanyaan kuisioner konsisten dan reliable. Hasil kuisioner selanjutnya diuji dengan uji koefisien regresi dan di dapatkan hasil t hitung 2,616 > t table 2,042, dimana hal ini menerangkan faktor kepuasan $\left(\mathrm{X}_{1}\right)$ dalam bekerja mempunyai pengaruh yang signifikan dan dominan terhadap pembangunan kinerja karyawan (employee performance), sedangkan turnover, pelatihan dan produktivitas karyawan secara bersama-sama tidak berpengaruh signifikan dan nyata terhadap peningkatan kinerja karyawan (employee performance) melalui metode balanced scorecard.

\section{Saran}

1. Memperbaiki kondisi-kondisi yang menumbuhkan kenyamanan karyawan dalam bekerja. Selain itu, perbaikan kualitas pelatihan yang diberikan kepada karyawan harus selalu diperbaiki agar karyawan dapat melaksanakan pekerjaannya sebaik mungkin. 
2. Langkah-langkah yang dapat dilakukan perusahaan untuk meningkatkan kinerja karyawan adalah seperti: promosi karyawan, peningkatan upah pokok serta tunjangan, menerapkan kebijakan (peraturan) perusahaan secara tegas dan konsisten agar tidak di anggap berpihak terhadap pihak-pihak tertentu. Menjalankan metode pengukuran kinerja yang sudah di tentukan secara konsisten berdasarkan penilaian yang obyektif.

\section{DAFTAR PUSTAKA}

Alwi, S. (2001). Manajemen Sumber Daya Manusia: Strategi Keunggulan.

Kaplan, R. S., \& Norton, D. P. (1996). Balanced Scorecard: Menerapkan Strategi Menjadi Aksi. Jakarta: Erlangga.

Kotler, P. (Editor AB. Susanto). (2000). Manajemen Pemasaran di Indonesia (Analisis, Perencanaan, Implementasi dan Pengendalian). Jakarta: Salemba Empat.

Mulyadi. (2001). Balanced Scorecard: Alat Manajemen Kontemporer untuk Pelipatgandaan Kinerja Keuangan Perusahaan. Jakarta: Salemba Empat.

Nurlaila. (2010). Manajemen Sumber Daya Manusia I. Ternate: LepKhair.

Sugiyono. (2012). Metode Penelitian Kuantitatif Kualitatif dan R\&D. Bandung: Alfabeta. 